\title{
Strategi Komunikasi Antar Budaya Tentara Nasional Indonesia (TNI) di Papua
}

\author{
Eka Prabawa $^{1 *}$, Joni Widjayanto ${ }^{2}$, Yusuf Ali ${ }^{3}$, Herlina Saragih ${ }^{4}$, \\ Aris Sarjito $^{5}$, Siska Armawati Sufa ${ }^{6}$ \\ 1,2,3,4,5 Universitas Pertahanan Republik Indonesia, \\ ${ }^{6}$ Universitas Padjadjaran Bandung \\ *E-mail: ekaprabawa5@doktoral.idu.ac.id
}

\begin{abstract}
Abstrak
Kemajemukan merupakan kekayaan dan modal sosial yang sangat baik. Pada sisi lain, kemajemukan memiliki potensi konflik laten yang dapat mengancam keamanan, dan perdamaian di masyarakat. Sebagai salah satu provinsi di Indonesia yang memiliki tingkat pluralisme yang kompleks, Papua ditinggali oleh berbagai suku asli Papua dan suku yang berasal dari luar Provinsi Papua. Dalam artikel ini, peneliti menguraikan strategi komunikasi yang dilakukan oleh Tentara Nasional Indonesia (TNI) yakni Kodam XVII Cenderawasih dan Lantamal X Jayapura. Kedua institusi yang merupakan institusi Tentara Nasional Indonesia (TNI) dalam bertanggung jawab menciptakan situasi kondusif di masyarakat. Penelitian ini merupakan penelitian kualitatif. Data dikumpulkan dengan wawancara dan studi pustaka. Hasil penelitian menunjukkan bahwa penerapan strategi komunikasi antar budaya oleh TNI sebagai wujud kemanunggalannya dengan rakyat, yaitu: smart-power, yang terdiri dari Soft power diterapkan kepada pihak non bersenjata, sedangkan hard power diterapkan kepada kelompok sipil yang bersenjata. Strategi komunikasi antar budaya dilakukan dengan pendekatan agama, budaya, dan kesetaraan. Penelitian ini diharapkan dapat menjadi bahan evaluasi bagi Kodam XVII Cendrawasih dan Lantamal X Jayapura.
\end{abstract}

Kata Kunci: Komunikasi antar budaya, Konflik, Papua, TNI

\begin{abstract}
Pluralism is an excellent wealth and social capital. On the other hand, pluralism has the potential for latent conflicts that can threaten security and peace in society. As one of the provinces in Indonesia that has a complex level of pluralism, Papua is inhabited by various indigenous Papuan tribes and tribes originating from outside the Papua Province. In this article, the researcher describes the communication strategy carried out by the Cenderawasih Military Command XVII and Jayapura X Lantamal. The two institutions which are the institutions of the Indonesian National Armed Forces (TNI) are responsible for creating a conducive situation in society. This research is a qualitative research. Data were collected by interview and literature study. The results of the study indicate that the application of intercultural communication strategies by the TNI as a form of its unity with the people, namely: smart-power, which consists of soft power is applied to non-armed parties, while hard power is applied to armed civilian groups. The strategy of intercultural communication is carried out with a religious, cultural, and equality approach. This research is expected to be an evaluation material for Kodam XVII Cendrawasih and Lantamal X Jayapura.
\end{abstract}

Keywords: Intercultural communication, Conflict, Papua, TNI 


\section{PENDAHULUAN}

Negara Kebangsaan merupakan negara yang terbentuk atas dasar semangat kebangsaan dan nasionalisme. Kehidupan multikultur dapat hidup berkembang dengan baik di lingkungan negara kebangsaan, bahkan menjadikan kehidupan multikultur berkembang dengan keberagamannya yang tetap terikat dalam identitas nasional. Masyarakat yang berada dalam negara kebangsaan berasal dari berbagai kelompok etnik, ras, golongan, dan agama memiliki berbagai pola hidup, sudut pandang, dan adat-istiadat berbeda. Keragaman yang dimiliki oleh negara kebangsaan dalam hal etnik dan ras menciptakan istilah baru yaitu interaksi antar etnik dan interaksi antar ras. Perbedaan ras, etnik, agama, dan golongan merupakan salah satu hambatan dalam proses komunikasi yang sangat potensial di masyarakat (Anwar, 2018; Moulita, 2018; Putra et al., 2018).

Proses komunikasi yang terjadi di masyarakat dengan perbedaan suku, agama, ras, dan budaya yang biasa disebut dengan komunikasi multikultural melibatkan interaksi antar individu maupun kelompok. (Alif, 2016; Alviana, 2015; Anwar \& Cangara, 2016; Arief Sigit Muttaqien, 2009; Barus \& Barus, 2019; bin Raji, 2019; Budiarti \& Yuliani, 2020; Hasibuan \& Muda, 2017, 2018; Karim, 2016). Proses komunikasi ini perlu dipahami sesama individu agar tercipta ruang dan lingkungan yang harmonis. Masyarakat yang harmonis tentunya memerlukan interaksi atau pola hubungan yang setiap sistemnya berfungsi secara efektif (Anwar, 2018; Moulita, 2018; Putra et al., 2018).

Komunikasi antar budaya secara istilah dapat digunakan secara luas untuk semua bentuk komunikasi diantara orang-orang yang berasal dari kelompok yang berbeda, selain itu juga digunakan secara lebih sempit, yang mencakup komunikasi antara kultur yang berbeda (M Ridwan Yunus \& Irwan, 2018; Mahmudah \& Mansyur, 2021; Mogot et al., 2016; Mohamad Sudi, 2020; Muttaqien, 2009; Noro Iswari, 2017; Nuryanti, 2018; Pakpahan, 2013; Pratiwi, 2021; Putra et al., 2018; Rasul, 2016; Roth, 2013; Santoso \& Fatimah, 2021; Sari, 2018; Situmorang et al., 2020; Sunani, 2019; Suparlan, 2013).

Komunikasi merupakan proses transaksi untuk mencapai tujuan tertentu. Komunikasi dapat terwujud secara efektif apabila antara komunikator dan komunikan memiliki kesamaan pemahaman pesan, sedangkan komunikasi sosial budaya yaitu proses komunikasi yang melibatkan orang-orang yang berasal dari lingkungan sosial budaya yang berbeda (M Ridwan Yunus \& Irwan, 2018; Mohamad Sudi, 2020).

Papua adalah sebuah provinsi yang merupakan bagian dari negara Indonesia, Papua juga disebut sebagai Papua Barat karena posisi Papua berada di Pulau Nugini bagian barat. Provinsi Papua juga pernah dikenal dengan sebutan Irian Barat, mulai tahun 1969 sampai tahun 1973, yang penamaanya dirubah kembali menjadi Irian Jaya oleh Presiden Soeharto, bersamaan dengan peresmikan tambang tembaga dan emas Freeport. nama yang tetap digunakan secara resmi hingga tahun 2002.

Provinsi Papua memiliki asal-usul dari ras Melanesia, yang di dalamnya terbagi beberapa suku dari 200-300 suku yang memiliki ciri khas tertentu, akan tetapi penduduk suku non-Melanesia juga banyak yang menghuni di Provinsi Papua hingga 3 generasi. Masyarakat Papua lebih dominan menganut organisasi gereja yang dipercaya mereka, menganut ajaran cinta kasih yang juga diajarkan kitab suci agama lain. 
Terkait tingkat kesejahteraan, jumlah penduduk di Papua pada tahun 2020 berjumlah 4,30 juta jiwa, atau meningkat sebesar 1,47 juta jiwa dari tahun 2010. Dari jumlah tersebut, sekitar 3,99 juta warga berdomisili sesuai dengan KK dan KTP. Sedangkan sekitar 308 ribu penduduk yang lain tidak sesuai data kependudukan.

Saat ini, suku Jawa lebih mendominasi dari penduduk asli Papua. Kebanyakan penduduk non Papua berasal dari suku Jawa. Mereka datang melalui program transmigrasi, serta mandiri yang didasarkan atas keinginannya sendiri. Sebagai contoh Kabupaten Merauke, perpindahan suku Jawa ke daerah Merauke ditaksir sekitar diperkirakan 275.000. Perpindahan tersebut terhitung sejak program transmigrasi itu dimulai. Pendatang rata-rata menguasai beberapa sektor di Provinsi Papua. Sektor-sektor tersebut dari bidang pertanian, bisnis, pemerintahan, dan lain-lain. Selain suku Jawa, suku lain juga banyak yang tinggal di Papua. Suku tersebut di antaranya adalah Bugis Makassar, Maluku, Sunda, dan Manado. Penduduk di wilayah Kota Nabire, lebih banyak ditemukan orang Jawa daripada orang Wate yang merupakan suku asli Nabire.

Pemerintah saat ini memprioritaskan pembangunan di provinsi Papua. Mulai dari pembangunan jalan raya, transportasi laut, serta udara. Pembangunan ini bertujuan untuk mewujudkan keadilan, meratanya pembangunan, meminimalisir kesenjangan sosial. Selain itu pemerintah memperhatikan Papua melalui kebijakan dengan pendekatan kesejahteraan agar tercipta hubungan baik antarwilayah maupun antar penduduk. Kesejahteraan Sosial yang diatur pada Undang-undang No. 11 Tahun 2009 dimaknai dengan terpenuhi keperluan setiap penduduk. Keperluan tersebut dinilai dari material, spiritual serta sosial. Menjadikan penduduk Papua menjadi lebih layak untuk hidup. Apabila kesejahteraan penduduk kurang baik, maka hal ini akan menyebabkan suatu hambatan dalam menjalankan kehidupan yang lebih baik dan tertata di Wilayah Papua. Hingga saat ini penanggulangan terhadap permasalahan tersebut bisa dikatakan sudah berjalan. Hal ini dibuktikan dengan banyaknya program yang dibuat pemerintah guna mengatasi kemiskinan. Jawaban dari adanya permasalahan di Papua bisa dilihat dari implementasi kebijakan otonomi khusus Provinsi Papua, meskipun belum berdampak sangat besar dan siknifikan untuk menanggulangi kemiskinan yang terjadi di Papua.

Sikap pejabat yang belum bisa maksimal memanfaatkan kewenangan yang dimiliki, membuat tujuan kebijakan belum optimal, kondisi ini menyebabkan efektivitas program kesejahteraan yang sudah dijalankan, belum sepenuhnya efektif. Sikap yang menjadi kendala membuat kesejahteraan penduduk asli Papua kurang diperhatikan. Sementara antusiasme cukup baik datang dari masyarakat yang turut berpartisipasi dalam proses pembangunan. Di antara aspek yang cukup baik ialah kesehatan ekonomi, budaya, dan agama, akan tetapi aspek pendidikan di Papua belum bisa dikatakan baik dan setara dengan wilayah lain.

UU No. 21 tahun 2001 tentang Otonomi Khusus bagi Provinsi Papua mengatur bahwa multikultur sebagai suatu realitas yang wajib ditumbuhkembangkan dalam wujud penghargaan terhadap pluralisme. Hal ini tentunya diwarnai dengan keberpihakan secara tegas kepada masyarakat yang hidup di daerah terdepan, tertinggal, dan terpencil (daerah 3T) serta memiliki hirarki paling bawah di masyarakat, dalam proses memperoleh akses terhadap berbagai fasilitas kesejahteraan sosial, ekonomi, dan budaya. 
Sebagai komando pertahanan wilayah daratan dan lautan di Provinsi Papua, kebijakan Komando Daerah Militer (Kodam) XVII Cendrawasih, dan Pangkalan Utama TNI AL (Lantamal) X Jayapura yang merupakan bagian dari Tentara Nasional Indonesia (TNI) memiliki tanggung jawab untuk mengidentifikasi, mencegah, hingga meredam konflik yang timbul di Papua. Suatu resolusi dianggap tepat dan berhasil jika konflik yang sama tidak berulang kembali. Namun, dalam implementasinya tidak akan mudah, utamanya bila terkait dengan komunikasi antar budaya. Komunikasi yang terkait dengan pihak yang memiliki latar belakang yang berbeda, dan memiliki penilaian pandang tersendiri dalam merespons dan menyelesaikan suatu masalah, maka strategi komunikasi antar budaya menjadi sangat penting dilakukan.

Edward T. Hall menyatakan, "Culture is communication" dan "Communication is culture". Dengan kata lain, budaya merupakan bagian dari sikap untuk berkomunikasi, serta komunikasi menentukan perkembangan dan kewarisan dari sebuah budaya. Komunikasi dan budaya bisa dikatakan dua hal saling memiliki relasi atau keterikatan (Mulyana \& Rakhmat, 1990).

Komunikasi lintas budaya merupakan fenomena yang sangat dinamik. Hal ini disebabkan karena proses tersebut dipengaruhi oleh konsep yang dikategorikan sebagai faktor sosiologi, psikologi, dan budaya. Sesuai dengan penjelasan Gudykunst dan Kim bahwa konsep di atas memiliki pengaruh pada proses interaktif penyandian pesan dan penyandian balik pesan. Tidak jarang komunikasi antar budaya sering kali menyebabkan timbulnya prasangka buruk kepada orang lain. Penyebab fenomena tersebut disebabkan karena adanya perbedaan dari segi nilai-nilai dan sosio-psiko budaya.

Dalam melakukan membuat strategi komunikasi dengan audiens yang heterogen, tentu saja pembuat strategi perlu untuk melakukan riset terlebih dahulu mengenai perilaku komunikasi audiens. Terlebih jika audiens terdiri dari multi kultur. Multikultural ini dapat menjadi tantangan sekaligus hambatan. Hal ini dikarenakan defisini dari komunikasi antarbudaya dapat dipahami sebagai proses komunikasi yang melibatkan orang-orang yang memiliki latar belakang sosial budaya yang berbeda. Komunikator dan komunikan dalam hal ini sering dihadapkan dalam kesalahan penafsiran pesan karena masing-masing individu memiliki budaya yang berbeda.

Kodam XVII Cendrawasih dan Lantamal X Jayapura pun menyadari sepenuhnya mengenai fenomena komunikasi yang terjadi di wilayah Papua. Terdapat dua suku yang menjadi penduduk mayoritas dalam wilayah tersebut yakni penduduk Papua dan penduduk Jawa. Agar tercipta komunikasi yang efektif, dibutuhkan kesamaan pengertian atau pemahaman yang lebih komprehensif. Salah satu caranya adalah dengan mempelajari budaya orang lain yang memiliki budaya yang berbeda (Suryani, 2013).

Komunikasi yang efektif dapat terwujud jika strategi dan metode komunikasi yang digunakan tepat. Strategi komunikasi yang efektif sangat penting diperhatikan dalam sebuah proses komunikasi. Dalam kalangan militer, terdapat ungkapan, "to win the war, not to win the battle". Ungkapan tersebut dapat dipahami bahwa memenangkan perang bukan memenangkan pertempuran. Pentingnya strategi adalah untuk memenangkan perang, sedangkan pentingnya taktik adalah untuk memenangkan pertempuran. Dengan kata lain, seorang praktisi komunikasi seharusnya fokus pada strategi komunikasi (Effendy, 1986). 
Strategi komunikasi antar budaya diperlukan karena dapat menghasilkan dampak yang positif, seperti: (1) Memahami dan menggunakan bahasa yang baik; (2) Memahami norma dan karakter lawan bicara; (3) Prasangka yang positif terhadap lawan bicara. Dengan demikian, komunikasi lintas budaya dapat berperan baik dalam membingkai perbedaan dalam persatuan (Muhajir \& Anismar, 2021).

Hambatan utama yang dialami oleh orang Papua saat berkomunikasi dengan etnis lain adalah faktor keengganan untuk berkomunikasi. Keengganan ini disebabkan oleh kuatnya stereotipe yang mengakibatkan perasaan ketidaksetaraan warga Papua ketika melakukan aktivitas komunikasi. Dengan kata lain, orang Papua berupaya untuk menyesuaikan diri, sedangkan suku lain tidak demikian. Kepercayaan diri dari orang Papua untuk berkomunikasi dengan etnis lain perlu diapresiasi karena mereka memiliki kepercayaan diri yang cukup tinggi (Prabowo \& Fatonah, 2014).

Berdasarkan uraian latar belakang tersebut, Aktivitas komunikasi yang dijalankan di Papua sarat akan dengan komunikasi antarbudaya dan diperlukan strategi komunikasi khusus untuk itu. Strategi komunikasi pun dijalankan oleh Kodam XVII Cendrawasih dan Lantamal $\mathrm{X}$ Jayapura sebagai upaya mencari jalan tengah antara penduduk Papua dan penduduk Jawa. Hal ini dimaksudkan agar pesan-pesan yang disampaikan dalam strategi komunikasi mereka dapat diterima dengan baik oleh kedua belah pihak. Dengan demikian, tujuan strategi komunikasi dapat tercapai (Mulyana \& Rakhmat, 1990; Effendy, 1986). Artikel ini dimaksudkan untuk mengetahui strategi dan tujuan komunikasi yang dilakukan oleh Tentara Nasional Indonesia (TNI) yang ada di Papua dalam hal ini Kodam XVII Cendrawasih dan Lantamal X Jayapura.

\section{METODOLOGI PENELITIAN}

Penelitian ini adalah penelitian kualitatif deskriptif. Penelitian ini bertujuan untuk memotret dan menarasikan sebuah fenomena, peristiwa, dan kejadian yang telah terjadi (Mulyana, 2001; Sugiyono, 2015). Penelitian yang bersifat deskriptif merupakan penelitian yang memfokuskan pada masalah aktual sebagaimana mestinya pada saat penelitian berlangsung dan tanpa memberikan perlakuan khusus terhadap peristiwa tersebut.

Teknik pengumpulan data dilakukan dengan wawancara, observasi, dan studi pustaka. Key infomans dalam penelitian ini ditentukan dengan teknik purposive sampling. Peneliti menetapkan sejumlah kriteria yakni informan terlibat dalam perencanaan, implementasi, hingga evaluasi dari strategi komunikasi yang dijalankan. Selain itu, informan juga memiliki kapabilitas dan kredibilitas yang baik sehingga data yang didapatkan peneliti dapat dipertanggung jawabkan validitasnya. Terakhir, informan juga terbuka serta jujur terhadap pertanyaan peneliti dan bersedia diwawancara oleh peneliti. Adapun key infomants dalam penelitian ini adalah: (1) Kolonel Arh. Ignatius Wahyu Jatmiko M.D.S., selaku Asren. Kasdam. XVII/Cenderawasih; (2) Letkol. Laut (T) I.G.K. Hans Desember, Amd., M.Han., selaku Dantim. Intel. Lantamal X Jayapura.

Analisis data penelitian dilakukan dengan reduksi data, penyajian data, dan menarik kesimpulan dari Miles dan Huberman. Teknik validitas yang dilakukan dalam penelitian ini adalah dengan melakukan validitas sumber penelitian (Mulyana, 2001; Sugiyono, 2015). 


\section{HASIL DAN PEMBAHASAN}

Strategi komunikasi dibutuhkan dalam penanganan konflik yang terjadi di Papua. Strategi komunikasi yang dijalankan oleh Kodam XVII Cendrawasih dan Lantamal X Jayapura tidak lepas dari pertimbangan banyaknya budaya yang ada di sana. Banyaknya budaya yang ada di tanah Papua memiliki pengaruh terhadap cara individu untuk menyesuaikan diri untuk bertahan hidup serta berkembang. Akan tetapi kelompok tersebut memiliki ragam gaya hidup, bermacam cara pandang serta adat istiadat yang berbeda. Banyaknya perbedaan etnis dan ras memunculkan interaksi antar keduanya. Adanya interaksi tersebut kerap kali menjadi hambatan dalam melangsungkan suatu komunikasi.

Adanya berbagai perbedaan yang disebabkan oleh komunikasi tersebut terdapat suatu cita-cita untuk menciptakan harmoni kebersamaan. Secara simbolik komunikasi tersebut disatukan dengan sukarela guna menciptakan rukun sejahtera dan penuh kedamaian. Berawal dari komunikasi, maka akan menyebabkan jarak dan pertentangan yang ada, manjadi perlahanlahan akan menjadi hilang. Fenomena demikian bisa terjadi dikarenakan adanya transaksi emosional dan rasional. Transaksi tersebut berwujud sebuah ide dan gagasan yang mampu ditukarkan secara terus-menerus dalam posisi yang sejajar. Hal ini akan membuat masyarakat mampu merasakan kebahagiaan, kegembiraan, suka cita, kasih sayang bahkan juga kesedihan, serta pada kebersamaan. Transaksi emosional dan rasional akan memunculkan gagasan dan ide yang dipertukarkan secara terus-menerus, berkembang dalam konteks kederajatan. Hal ini menyebabkan seseorang bisa merasakan bahagia, sedih, suka, cinta dan kasih sayang. Komunikasi juga sebagai penyebab mencairnya jarak dan pertentangan yang sebelumnya terjadi.

Dalam proses interaksi antar budaya, maka konteks komunikasi dan budaya tidak dapat dipisahkan, karena latar belakang budaya mempengaruhi cara berkomunikasi, baik dalam menerima pesan maupun cara interaksi komunikator dalam menyampaikan pesan. Dalam lingkup budaya, komunikasi tidak hanya terkait bahasa, tetapi juga laku, adat, nilai, hingga interpretasi dari perspektif individu.

Perilaku komunikasi juga dipengaruhi oleh faktor budaya. Sikap yang ditunjukkan merupakan interpretasi konteks hubungan yang berpengaruh terhadap komunikasi antar budaya. Pesan nonverbal memiliki pengaruh pada proses komunikasi di lingkungan masyarakat Papua. Sebab bahasa tubuh yang ditunjukkan lawan bicara memiliki perbedaan dengan masing-masing suku yang ada. Sementara hambatan yang ditemui masyarakat Papua dengan para pendatang merupakan masalah komunikasi yang verbal. Komunikasi ini dipengaruhi dari dialog, intonasi, dan dari suara lawan saat bicara.

Hasil dari strategi komunikasi sebagai penyelesaian konflik oleh Kodam XVII Cendrawasih dan Lantamal X Jayapura terlihat dari tingkat kesejahteraan masyarakat dan kebijakan pemerintah pusat dalam membangun Papua melalui pendekatan kesejahteraan. Upaya kemanunggalan TNI dengan rakyat Papua baik di wilayah daratan di bawah naungan Kodam XVII Cendrawasih dan di wilayah lautan di bawah naungan Lantamal X Jayapura menjalankan beberapa strategi komunikasi sosial budaya dengan metode smart power. 
Strategi smart power meliputi soft power dan hard power. Soft power diterapkan kepada pihak non bersenjata, sedangkan hard power diterapkan kepada kelompok sipil yang bersenjata. Pembagian tersebut sejalan dengan kebijakan pemerintah pusat yang bertujuan dalam pembangunan Papua. Implementasi dari strategi ini diwujudkan oleh Kodam XVII Cenderawasih dan Lantamal X Jayapura dengan melaksanakan tiga pendekatan yaitu agama, budaya, kesetaraan. Dalam mengimplementasikan strategi komunikasi ini, kedua institusi tersebut menyadari bahwa komunikasi yang terjalin baik dapat lebih mudah menyelesaikan permasalahan dan konflik (Jatmiko, 2021; Hans, 2021).

Pertama, Soft Power diimplementasikan dalam kegiatan Babinsa Koramil Beoga bersama Sat BKO. Target audiens dalam kegiatan ini adalah wilayah Distrik Beoga. Tepatnya di kampung Milawak Babinsa Koramil 1714-05/Beoga bersama dengan satgas APTER. Kegiatan ini dimaksudkan untuk menjalin kedekatan dengan masyarakat mewujudkan stabilitas keamanan, dan ketentraman.

Dalam kegiatan ini, Babinsa Koramil 1714-05/Beoga menghimbau kepada masyarakat untuk mencagah adanya gangguan keamanan. Selain itu, menerapkan pola hidup bersih dengan mencuci tangan, menggunakan masker saat beraktivitas, dan berkomunikasi dengan teman maupun keluarga yang lain, serta mengajak masyarakat berdoa bersama agar dijauhkan dari Covid-19 khususnya di wilayah distrik Beoga.
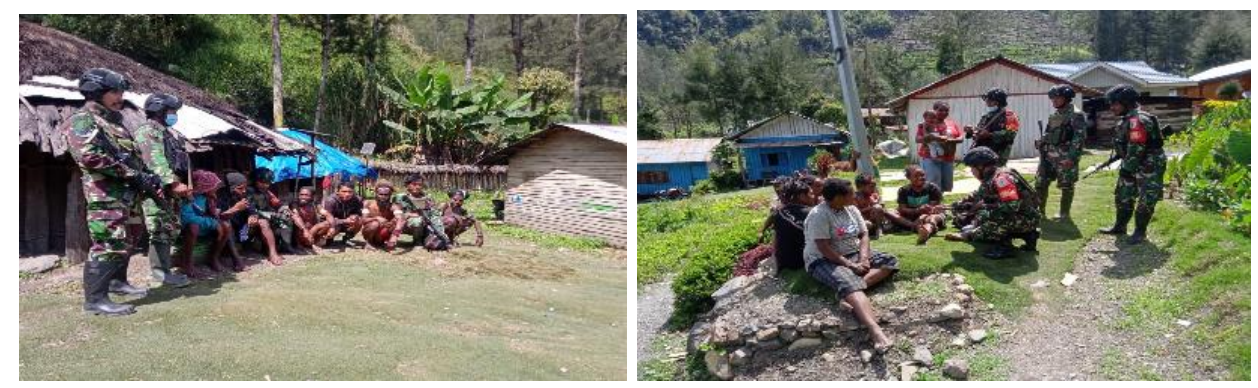

Gambar 1. Implementasi Strategi Komunikasi dengan Pendekatan Soft Power

Implementasi soft power lainnya oleh Kodam XVII Cendrawasih diwujudkan dalam perekrutan prajurit TNI dengan lebih mengutamakan Putera daerah asal Papua. Persentase perekrutan putera daerah asli Papua adalah $80 \%$ dan dari kalangan pendatang adalah $20 \%$. Hal ini bertujuan agar terdapat peningkatan kualitas sumber daya manusia dari orang asli Papua.

Upaya lain dalam menciptakan situasi kondusif di wilayah Papua, khususnya Jayapura adalah dengan melakukan penggalangan dengan masyarakat. Terutama saat menjelang peringatan hari kelahiran Organisasi Papua Merdeka pada 01 Desember 2021 lalu, Tim Intelejen dari Lantamal X Jayapura melakukan beberapa hal, diantaranya: 1) Selalu update setiap perkembangan situasi di seluruh wilayah naungan secara tepat dan cepat; 2) Memberikan informasi perkembangan situasi wilayah tersebut kepada seluruh elemen masyarakat, baik militer maupun aparatur sipil negara; 3) Melakukan latihan strategi taktik perang, dalam bentuk latihan operasi intelejen, latihan menembak, cara penanggulangan aspek terorisme, pencegahan serta rute pelolosan apabila terjadi keadaan yang semakin darurat. 

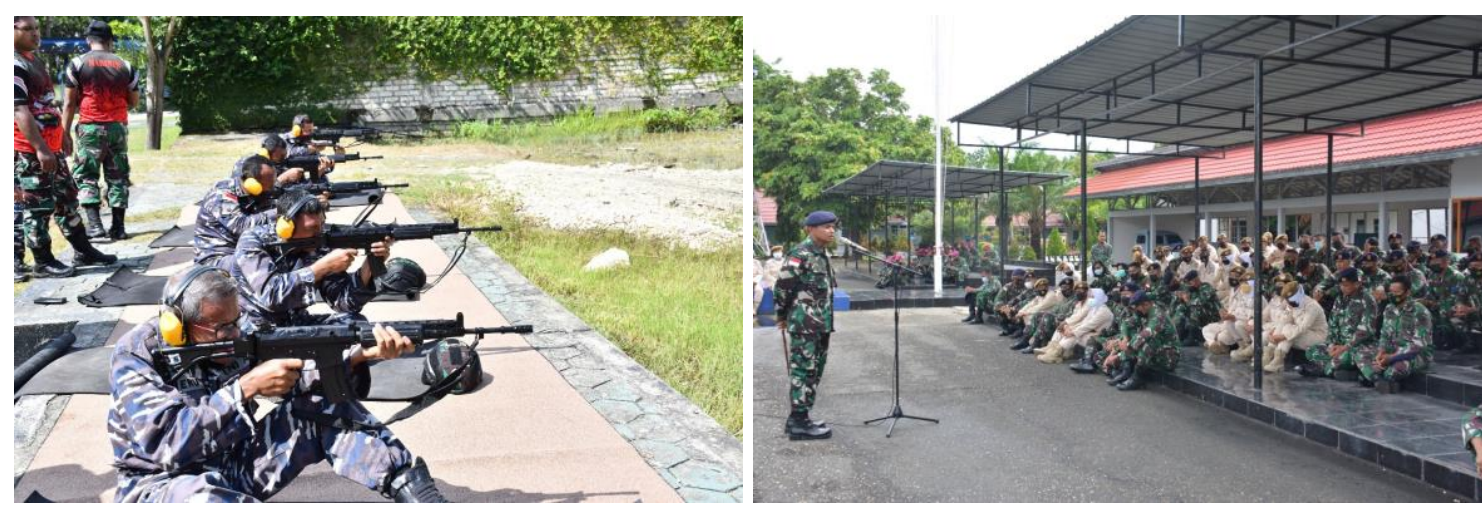

Gambar 2. Upaya Lantamal X Jayapura menciptakan situasi kondusif jelang peringatan hari kelahiran Organisasi Papua Merdeka pada 01 Desember 2021

Kedua, Hard Power diimplementasikan oleh Babinsa Koramil 02/Napan Sertu Setyo Triono dengan melaksanakan kegiatan karya bakti bersama warga binaannya. Salah satu kegiatan yang dijalankan adalah dengan memasang gorong-gorong sumur milik Sutris, salah satu warga kampung Legari Jaya, Distrik Makimi, Kabupaten Nabire. Kegiatan ini diharapkan akan dapat menumbuhkan budaya gotong-royong serta tumbuhnya semangat dan nilai-nilai kekompakan. Alhasil, pada akhirnya dapat menjadikan motivasi bagi masyarakat saling membantu antar sesama.

Dalam sudut pandang TNI, kegiatan ini dimaksudkan untuk mewujudkan kemanunggalan TNI dengan rakyat agar tetap terjalinnya hubungan yang baik. Hubungan yang baik ini kemudian dapat memperlancar pembinaan teritorial dan dapat membantu kesulitan rakyat sekelilingnya.
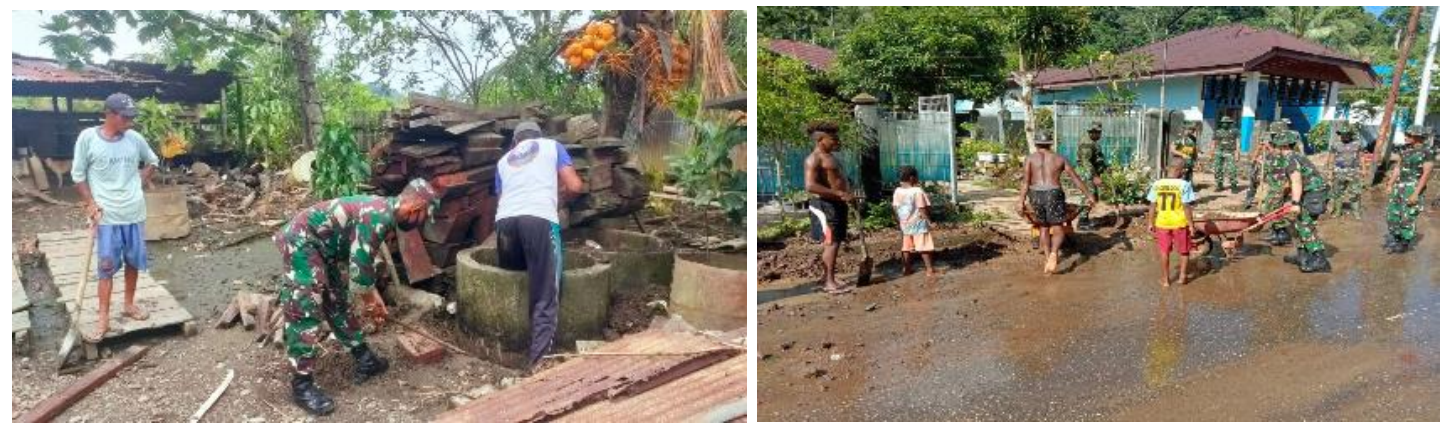

Gambar 3. Implementasi Strategi Komunikasi dengan Pendekatan Hard Power

Dalam konsep komunikasi antar budaya, tidak dapat dipungkiri adanya proses adaptasi budaya antara etnik Papua dan etnik Jawa. Pengaruh proses adaptasi melahirkan proses akomodasi budaya kemudian memberikan dampak pada perilaku dan model komunikasi. Pengaruh ini merupakan salah satu dampak proses adaptasi (Gudykunst, 2003).

Aspek lain dalam komunikasi antar budaya adalah budaya, budaya sosial, dan budaya psikologi (Gudykunst, 2003). Budaya merupakan poin utama dalam komunikasi antar budaya. Budaya berpengaruh terhadap cara berkomunikasi orang Papua, demikian halnya orang Jawa. Budaya dalam berkomunikasi tidak dapat dihilangkan serta merta meski manusia berpindah 
tempat. Perbedaan budaya ini dapat diatasi dengan strategi komunikasi yang dijalankan oleh Kodam XVII Cendrawasih melalui program-program kesetaraan dan kesejahteraan.

Beberapa budaya yang peneliti lihat berpengaruh dalam cara berkomunikasi orang asli Papua dengan orang jawa adalah budaya sosial dan budaya psikologi. Budaya sosial memiliki kemungkinan kecil untuk berubah (Gudykunst, 2003). Adapun budaya psikologi merupakan bentukan dari proses budaya perilaku individu ketika menyelesaikan suatu masalah (Gudykunst, 2003). Orang Jawa dan Papua memiliki karakteristik tersendiri, namun dapat dijembatani dengan adanya proses adaptasi yang sarat akan empati satu sama lain. Ditambah dengan bentukan dari budaya sosial. Di samping itu, terdapat dukungan dari strategi komunikasi yang dilakukan oleh Kodam XVII Cendrawasih melalui program-program yang bertujuan untuk mencapai kesejahteraan masyarakat.

Dalam strategi komunikasi yang dijalankan, para pembuat strategi komunikasi sadar bahwa terdapat hambatan dalam strategi komunikasi. Strategi komunikasi yang dijalankan oleh Kodam XVII Cendrawasih memiliki tujuan akhir untuk menyejahterakan masyarakat yang berada di wilayah naungannya. Kodam XVII Cendrawasih berusaha untuk terus melakukan penyesuaian terhadap penanganan konflik dan memberikan edukasi untuk masyarakat dengan program yang telah dirancang sebelumnya.

Hasil observasi peneliti menunjukkan bahwa karakteristik orang Jawa adalah pandai mengendalikan sakit hati, iri, dan berambisi. Disamping itu, orang Jawa juga memiliki sikap tenang sehingga dapat membantu dalam pengendalian konflik. Orang Jawa dikenal pula dengan sikap ramah dan santun, saling mengasihi kepada orang yang lemah, mampu berkomunikasi dengan perasaan sedih atau senang terhadap orang lain. Namun demikian, orang Jawa memiliki kekurangan yakni beranggapan negatif terhadap orang diluar Jawa.

Orang Jawa yang bermukim di sekitar pesisir laut Jayapura yang merupakan wilayah naungan Lantamal X Jayapura menjunjung tinggi nilai toleransi. Orang Jawa menyadari betul bahwa mereka adalah pendatang. Dengan demikian tercipta keadaan yang saling menghormati satu sama lain. Saat awal kedatangan, masyarakat Jawa sadar betul bahwa mereka adalah pendatang dan perlu beradaptasi dengan lingkungan sekitar (Hans, 2021). Sifat asli dari orang Papua adalah kebebasan dalam berperilaku. Perilaku ini diterapkan ketika berada di luar wilayahnya. Hal ini membentuk sikap etnik Papua menjadi kurang peka terhadap norma dan aturan sosial di lingkungan baru (Hans, 2021).

Hasil dari observasi peneliti menunjukkan bahwa strategi komunikasi antar budaya yang dilakukan untuk menengahi konflik yang terjadi di Papua adalah perpaduan dari etnik Jawa dan Papua. Dengan demikian, sampai dengan saat ini tidak terjadi hal-hal yang tidak diinginkan, seperti permasalahan yang besar antar kedua etnik tersebut.

Hambatan utama dalam strategi komunikasi yang dijalankan adalah adanya perbedaan budaya. Hasil observasi yang dilakukan oleh peneliti menemukan bahwa terdapat sikap dari penduduk yang menganggap bahwa budaya mereka adalah budaya terbaik. Peneliti menemukan pada awalnya setiap suku memiliki prasangka negatif satu sama lain. Suku Papua berprasangka negatif terhadap suku Jawa, demikian sebaliknya. Lambat laun, prasangka 
negatif tersebut pun tergantikan dengan prasangka positif. Prasangka positif juga membuat penduduk Papua dan Jawa dapat saling berinteraksi.

Hasil obsevasi peneliti menunjukkan bahwa dialek yang terjadi antara penduduk Papua dan Jawa beraneka ragam. Hal ini dipengaruhi oleh letak geografis dan budayanya. Meski bahasa yang digunakan sama-sama bahasa Indonesia, pada saat berkomunikasi secara langsung, dialek yang terdengar berbeda-beda. Dialek penduduk Papua terkesan keras sedangkan penduduk Jawa terdengar pelan. Peneliti juga menemukan bahwa penduduk Jawa menganggap penduduk Papua kurang begitu jelas saat berkomunikasi. Bahasa Indonesia yang digunakan terdengar samar dan terbata-bata.

Hambatan dalam komunikasi yang terjalin antar dua etnis disebabkan perbedaan verbal, nonverbal, dan prasangka. Perbedaan verbal meliputi perbedaan bahasa, dialek dalam penyampaian. Sedangkan perbedaan nonverbal meliputi gerak atau bahasa tubuh saat berkomunikasi. Terakhir, prasangka sering kali terjadi antara dua etnis yang berbeda diakibatkan pemahaman yang minim antar suku yang berbeda.

Hambatan-hambatan dalam strategi komunikasi akibat adanya perbedaan budaya dapat diatasi dengan adaptasi budaya. Adaptasi budaya dapat dipahami sebagai proses perkembangan interaksi individu yang terjadi karena berhadapan dengan situasi lingkungan atau budaya yang baru. Proses ini ditandai dengan perilaku toleransi dan mau memahami, sehingga tercapai kesesuaian komunikasi yang menunjang terciptanya komunikasi yang efektif.

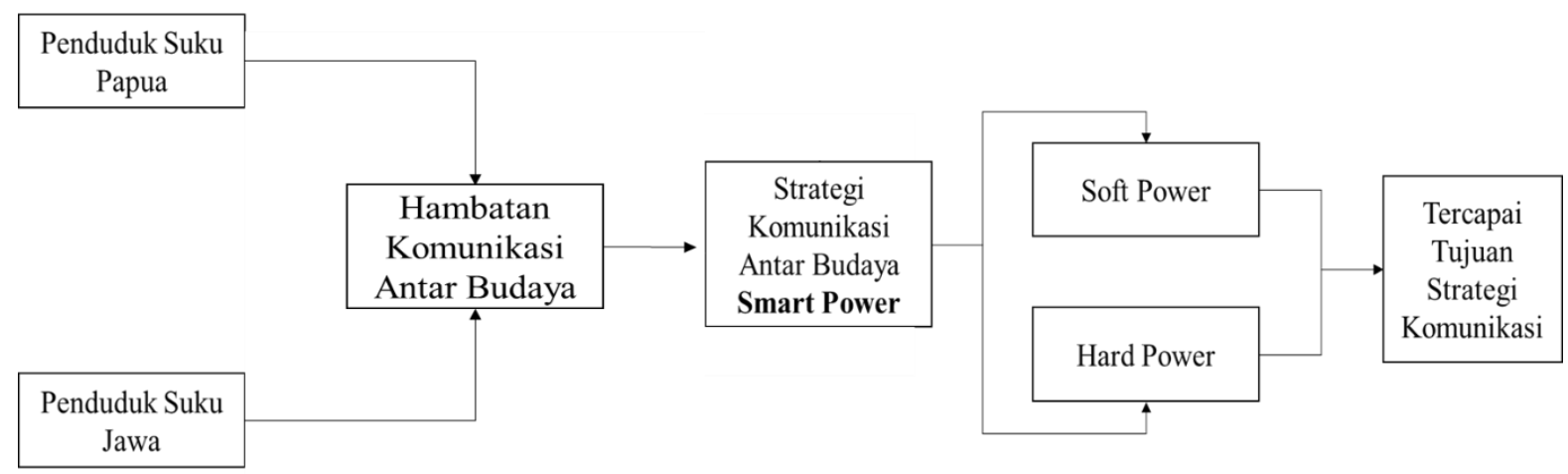

Gambar 4. Model Strategi Komunikasi Antar Budaya Smart Power

Gambar 4 merupakan model Strategi Komunikasi Antar Budaya Smart Power yang dijalankan oleh Tentara Nasional Indonesia (TNI) yakni Kodam XVII Cendrawasih dan Lantamal X Jayapura dimana pelaku strategi komunikasi memulai penyusunan strategi komunikasi dengan melakukan analisis terhadap perilaku komunikasi penduduk suku Papua dan penduduk suku Jawa. Kedua organisasi ini menemukan adanya persamaan dan perbedaan dari perilaku komunikasi kedua suku ini. Selanjutnya, pelaku strategi komunikasi mengidentifikasi tantangan dan hambatan dalam komunikasi antar budaya. Setelah selesai mengidentifikasinya, kedua instansi ini bekerja sama untuk merancang strategi komunikasi 
antar budaya yang dinamai dengan strategi Smart Power. Strategi komunikasi ini dibagi menjadi dua taktik yaitu soft power dan hard power. Kedua taktik strategi komunikasi ini kemudian mengantarkan Kodam XVII Cendrawasih dan Lantamal X Jayapura mencapai tujuan dari strategi komunikasi yang dijalankan di wilayah mereka.

Strategi komunikasi yang dijalankan dengan merangkul berbagai macam pihak yang berpengaruh kemudian diimplementasikan dalam Program Tentara Manunggal Membangun Desa (TMMD), Karya Bakti (perbaikan kampung, infrastruktur, rumah ibadah, sarana pendidikan, kesehatan), menjadi tenaga pendidik, tenaga kesehatan, dan aparatur pemerintah untuk membantu mengatasi kesulitan masyarakat.

\section{PENUTUP}

Strategi komunikasi yang dijalankan oleh Tentara Nasional Indonesia (TNI) yakni Kodam XVII Cendrawasih dan Lantamal X Jayapura dinamakan smart power yang terdiri dari soft power dan hard power yang didasarkan pada target audiens. Soft power memiliki target audiens tidak bersenjata. Sedangkan hard power adalah pihak-pihak yang bersenjata. Implementasi strategi komunikasi dilakukan dengan tiga pendekatan yaitu agama, budaya, dan kesetaraan.

Tujuan dari strategi komunikasi adalah untuk: (1) merangkul seluruh elemen masyarakat baik itu etnis Jawa dan Papua, (2) meningkatkan pemahaman mengenai sejarah Papua, (3) mendorong pembangunan dengan visi yang berpihak kepada rakyat, (4) mendorong pembangunan berbasis kearifan lokal dan penghormatan budaya Papua, (5) meningkatkan kualitas generasi muda (leadership, ilmu pengetahuan dan teknologi, olahraga, dan kesenian). Tujuan akhirnya adalah untuk mengatasi permasalahan kesejahteraan di Papua. Berbagai pihak yang terlibat dalam strategi komunikasi Kodam XVII Cendrawasih adalah lembaga adat, akademisi, budayawan, hingga koordinasi bersama Forum Komunikasi Pimpinan Daerah (Forkopimda).

Strategi komunikasi yang dijalankan dengan merangkul berbagai macam pihak yang berpengaruh kemudian diimplementasikan dalam Program Tentara Manunggal Membangun Desa (TMMD), Karya Bakti (perbaikan kampung, infrastruktur, rumah ibadah, sarana pendidikan, kesehatan), menjadi tenaga pendidik, tenaga kesehatan, dan aparatur pemerintah untuk membantu mengatasi kesulitan masyarakat.

\section{REFERENSI}

Alif, M. (2016). Komunikasi Antar Budaya Dalam Pernikahan Adat Minangkabau Di Kota Banjarbaru. Ppjp.Ulm, 1(1).

Alviana, S. (2015). Strategi Akomodasi Komunikasi Dalam Interaksi Antar Budaya Suku Melayu (Tempatan) dan Suku Jawa Di Desa Bukit Gajah Kecamatan Ukui Kabupaten Pelalawan Provinsi Riau by: Jom FISIP, 2(2).

Anwar, R. (2018). Hambatan komunikasi antarbudaya di Kalangan Pelajar. Common, 2(2). 
Anwar, R., \& Cangara, H. (2016). Rintangan Komunikasi Antar Budaya Dalam Perkawinan dan Perceraian Etnis Jawa dengan papua di kota Jayapura (Suatu Strategi Manajemen Konflik dalam Hubungan Interpersonal Suami Istri). Jurnal Komunikasi KAREBA, 5(2).

Arief Sigit Muttaqien, M. (2009). Komunikasi Antar Budaya (Study Pada Pola Komunikasi Masyarakat Muhammadiyah Dan NU Di Desa Pringapus, Semarang, Jawa Tengah). Jurnal Kajian Dakwah Dan Kemasyarakatan.

Barus, R. P., \& Barus, R. K. I. (2019). Komunikasi Antar Budaya pada Komunitas Aron di Berastagi. Jurnal Simbolika: Research and Learning in Communication Study, 5(2). https://doi.org/10.31289/simbollika.v5i2.2842

Bin Raji, K. ahmad. (2019). Komunikasi Antar Budaya Dalam Adat Perkawinan Jawa (Pendekatan Gudykunst dan Kim dalam Adat Perkawinan Jawa Oleh Pasangan Berbeda Budaya di Bengkulu Utara). Commed: Jurnal Komunikasi Dan Media, 4(1). https://doi.org/10.33884/commed.v4i1.1395

Budiarti, R., \& Yuliani, F. (2020). Strategi Adaptasi Culture Shock Dalam Komunikasi Antar Budaya Mahasiswa Papua Universitas Bengkulu (Studi Pada Mahasiswa Papua di Universitas Bengkulu). Jurnal Sarjana Ilmu Komunikasi, 1(2). https://doi.org/10.36085/j-sikom.v1i2.1105

Effendy, O. U. (1986). Dinamika komunikasi. Remadja Karya.

Gudykunst, W. B. (2003). Cross-cultural and intercultural communication. Sage.

Hasibuan, E. J., \& Muda, I. (2017). Komunikasi Antar Budaya pada Etnis Gayo dengan Etnis Jawa Intercultural Communication at The Gayo Ethnic and Javanese Ethnic. Simbolika, $3(2)$.

Hasibuan, E. J., \& Muda, I. (2018). Komunikasi Antar Budaya pada Etnis Gayo dengan Etnis Jawa. JURNAL SIMBOLIKA: Research and Learning in Communication Study, 3(2). https://doi.org/10.31289/simbollika.v3i2.1456

Karim, A. (2016). Komunikasi Antar budaya Di Era Modern. AT-TABSYIR: Jurnal Komunikasi Penyiaran Islam, 3(2).

Komunikasi Organisasi Antar Budaya di Lembaga Penjaminan Mutu Pendidikan Sumatera Utara. (2021). Jurnal Interaksi: Jurnal Ilmu Komunikasi, 5(1). https://doi.org/10.30596/interaksi.v5i1.5301

M Ridwan Yunus, \& Irwan. (2018). Komunikasi Antar Budaya Dilingkungan Iisip Yapis Biak Papua (Studi Tentang Komunikasi Antar Budaya Antara Mahasiswa Etnis Makassar Dengan Etnis Papua Semester Ii). Gema Kampus IISIP YAPIS Biak, 13(2). https://doi.org/10.52049/gemakampus.v13i2.34

Mahmudah, M., \& Mansyur, M. A. (2021). Komunikasi Antar Budaya Masyarakat Jawa Dan Madura. JKaKa:Jurnal Komunikasi Dan Konseling Islam, 1(1). https://doi.org/10.30739/jkaka.v1i1.805 
Muhajir, M., \& Anismar, A. (2022). Strategi Komunikasi Budaya Mahasiswa Papua dalam Interaksi dengan Mahasiswa Aceh di Universitas Malikussaleh. Jurnal Ilmu Sosial dan Ilmu Politik Malikussaleh (JSPM), 2(2), 301-311.

Mogot, G. I., Warouw, D. M. D., \& Waleleng, G. J. (2016). Komunikasi Antar Budaya Mahasiswa Etnis Batak Dengan Mahasiswa Etnis Jawa Di Kampus Ipdn Sulut. Keywords in Qualitative Methods.

Mohamad Sudi. (2020). Integrasi Sosial dalam Memahami Kehidupan Antaretnik Melalui Komunikasi Antar Budaya di Biak. Gema Kampus IISIP YAPIS Biak, 15(1). https://doi.org/10.52049/gemakampus.v15i1.106

Moulita. (2018). Hambatan Komunikasi AntarBudaya di Kalangan Mahasiswa. Common, 2(2).

Mulyana, D. (2001). Metodologi Penelitian Kualitatif: Paradigma Baru Ilmu Komunikasi dan Ilmu Sosial Lainnya. In Bandung: PT remaja Rosdakarya.

Mulyana, D., \& Rakhmat, J. (1990). Komunikasi antarbudaya. Remaja Rosdakarya.

Muttaqien, M. A. S. (2009). Komunikasi Antar Budaya (Study Pada Pola Komunikasi Masyarakat Muhammadiyah Dan NU Di Desa Pringapus, Semarang, Jawa Tengah). Jurnal Kajian Dakwah Dan Kemasyarakatan.

Noro Iswari, A. (2017). Komunikasi Antar Budaya di Kalangan Mahasiswa ( Studi tentang Komunikasi Antar Budayadi Kalangan Mahasiswa Etnis Batak dengan Mahasiswa etnis Jawa di Universitas SebelasMaret Surakarta ). Program Studi Ilmu Komunikasi Fakultas Ilmu Sosial Dan Ilmu PolitikUniversitas Sebelas Maret Surakarta.

Nuryanti, Dr. T. (2018). Faktor-Faktor Pembangun Dan Penghambat Kompetensi Komunikasi Antar Budaya Masyarakat Pegunungan Muslim Walesi DI Kota jayapura. JURNAL ILMU KOMUNIKASI, 1(1). https://doi.org/10.33005/jkom.v1i1.13

Pakpahan, F. B. (2013). Fungsi Komunikasi Antar Budaya Dalam Prosesi Pernikahan Adat Batak Di Kota Samarinda (Studi Kasus Empat Pasangan Berbeda Etnis Antara Batak dengan Etnis Jawa, Toraja, dan Dayak ). EJournal Ilmu Komunikasi, 1(3).

Prabowo, A., \& Fatonah, S. (2016). Kecemasan Komunikasi Dalam Relasi antar Etnik. Jurnal Ilmu Komunikasi, 12(3), 231-242.

Pratiwi, C. S. (2021). Model Komunikasi Antarbudaya Mahasiswa Muslim Thailand dalam Proses Akulturasi Budaya di Kabupaten Jember. Indonesian Journal of Islamic Communication, 3(2). https://doi.org/10.35719/ijic.v3i2.757

Putra, Y. P., Darmawan, A., \& Rochim, A. I. (2018). Hambatan Komunikasi pada Mahasiswa Perantauan Luar Jawa di Kampus Universitas 17 Agustus 1945 Surabaya (Studi Deskriptif Tentang Komunikasi Antar Budaya di Kalangan Mahasiswa Perantauan dari Luar Jawa dalam Menghadapi Culture Shock di Universitas 17 Agustus 1945 Surabaya). Representamen, 4(01). https://doi.org/10.30996/representamen.v4i01.1416 
Rasul, S. (2016). Proses Komunikasi Antar Budaya Studi Tentang Interaksi Pada Masyarakat Aceh Dan Jawa Di Desa Batu Raja, Nagan Raya. Skripsi Komunikasi, Fakultas Dakwah dan Komunikasi. Unive4rsitas Islam Negeri Ar-Raniry.

Roth, W. D. (2013). dinaamika komunikasi antar budaya dan agama di desa tawakua kabupaten luwu timur(studi kasus etnik bali dan jawa). International Migration Review, $47(2)$.

Santoso, B. B., \& Fatimah, F. (2021). Komunikasi antar Budaya Masyarakat Pedalaman Papua Melalui Model Komunikasi di Youtube Expedisi Segaris Episode 9. Jurnal Ilmiah $\begin{array}{llll}\text { Komunikasi } & \text { (JIKOM) STIKOM IMA, }\end{array}$ https://doi.org/10.38041/jikom1.v13i02.154

Sari, Y. A. (2018). Dinamika Komunikasi Antar Budaya Dalam Harmonisasi Santri Di Pondok Pesantren Darul A'mal Metro. IQRA' (Jurnal Kajian Ilmu Pendidikan), 3(1).

Situmorang, I. H., Hasibuan, E. J., \& Suharyanto, A. (2020). Culture Shock dalam Interaksi Komunikasi Antar Budaya pada Mahasiswa Asal Papua di Universitas Negeri Medan. Jurnal Ilmu Pemerintahan, Administrasi Publik, Dan Ilmu Komunikasi (JIPIKOM), 2(2). https://doi.org/10.31289/jipikom.v2i2.338

Sugiyono. (2015). Metode Penelitian Kuantitatif, Kualitatif, dan R\&D. Alfabeta.

Sunani, U. (2019). Interpretasi Makna Sapaan Mas Terhadap Etnik Jawa Di Makassar (Studi Komunikasi Antar-Budaya Di Makassar). Al-Mishbah, 15(2).

Suparlan, E. (2013). Dinamika Komunikasi ANtar Budaya dan Agama di Desa Tawakua Kabupaten Luwu Timur. In UIN Alauddin Makassar (Vol. 66). 